\title{
Evolução da norma ISO 9001: uma análise comparativa
}

Evolution of ISO 9001 standard: a comparative analyses.

\author{
Tarsila Tenório Luna da Silva ${ }^{1}$ \\ Ana de Fátima Braga Barbosa ${ }^{1}$ \\ ${ }^{1}$ Escola Politécnica de Pernambuco, Universidade de Pernambuco, Recife, Brasil, \\ E-mail do autor principal: Tarsila Tenório Luna da Silva tarsilatls@gmail.com
}

\section{Resumo}

Para garantir um alto nível e se adequar à realidade praticada nas organizações, as normas ISO são periodicamente revisadas. Esse trabalho apresenta a evolução da norma ISO 9001 desde sua publicação inicial até os dias atuais, contextualizando as mudanças de cenários econômicos e de mercado. Esta norma possui requisitos de qualidade e tem como objetivo a unificação de conceitos que facilitam a sistemática de aplicação da Gestão da Qualidade em serviços e processos. Atualmente já existem cinco versões: ISO 9001:1987, a pioneira que surgiu mediante a necessidade de uma norma de qualidade de abrangência mundial, sete anos após esta norma foi revisada nascendo a ISO 9001:1994, a versão ISO 9001:2000 veio com uma nova estrutura e enfoque adequado ao início do novo século, na ISO 9001:2008 houve outra revisão sem grandes alterações. A versão mais recente é a ISO 9001:2015 que, novamente, obteve grandes mudanças com a inclusão do Anexo SL com objetivo de unificar/definir estruturas, requisitos e terminologias de todas suas normas de sistemas de gestão.

Palavras-Chave: normas ISO 9001, qualidade, Gestão da Qualidade.

\begin{abstract}
To ensure a high level and adapt to the reality practiced in organizations, ISO standards are periodically reviewed. This work shows the evolution of ISO 9001 standards since their first edition until today, contextualizing changes in economic and marketplace scenery. This standard has qualities requirements for joint concepts to facilitate Quality Management and allows systematic application in service and processes. Five versions were issued since then: ISO 9001:1987, pioneer that emerged by necessity of scope world quality standard, after seven years this standard was reviewed bringing ISO 9001:1994, ISO 9001:2000 version received a new structure and appropriate approach to the beginning of the new century, the ISO 9001:2008 didn't have much changes. ISO 9001:2015 is the modern version with many changes, one of them, concept of Annex SL that has a purpose to join/define structure, requirements and terminology for all management systems standards.
\end{abstract}

Key-words: ISO 9001 standards, Quality, Quality Management. 


\section{Introdução}

O presente trabalho consiste em uma análise crítica da evolução das normas ISO 9001 para sistemas de gestão da qualidade. Estas normas são continuamente revisadas para garantir a sua adequação às evoluções nas exigências do mercado. A abordagem aplicada a este trabalho buscou analisar criticamente essas mudanças em relação às estruturas, aos enfoques e aos requisitos trazidos pela norma em cada nova versão, bem como, à aplicação dos conceitos: PDCA e kaizen. Adicionalmente, foi considerada a avaliação do cenário econômico do país e da visão do mercado em cada período.

Com a necessidade das empresas em avaliar seus fornecedores foi identificada a inexistência de um conjunto de normas, com objetivo de documentar e controlar sistemas de qualidade, definindo níveis de exigências com evidências objetivas e abrangência mundial. A era da Garantia da Qualidade precisava da normalização de serviços e processos. A família de normas série ISO 9000 veio para suprir esta necessidade. Atualmente, o mercado demostra maior abertura às organizações que estão em conformidade com as exigências das normas ISO 9001 [1][2][3].

A Tabela 1 apresenta os primeiros autores que estudaram a Qualidade e suas características.

Tabela 1: Pioneiros da qualidade

\begin{tabular}{|c|c|}
\hline Autores & Características \\
\hline Deming & $\begin{array}{l}\text { Controle estatístico de } \\
\text { processos; foco } \\
\text { gerencial; melhoria } \\
\text { contínua. }\end{array}$ \\
\hline Juran & $\begin{array}{c}\text { Controle de processos; } \\
\text { estratégia empresarial; } \\
\text { não negligenciar } \\
\text { oportunidades de } \\
\text { melhorias. }\end{array}$ \\
\hline Feigenbaum & $\begin{array}{c}\text { Controle total da } \\
\text { qualidade; estratégia } \\
\text { preventiva. }\end{array}$ \\
\hline Crosby & $\begin{array}{l}\text { Zero defeito; enfoque } \\
\text { preventivo. }\end{array}$ \\
\hline Ishikawa & $\begin{array}{l}\text { Círculo de controle da } \\
\text { qualidade; clientes } \\
\text { internos; 5S; enfoque } \\
\text { sistemático. }\end{array}$ \\
\hline Taguchi & $\begin{array}{c}\text { Estatística aplicada à } \\
\text { qualidade. }\end{array}$ \\
\hline
\end{tabular}

Fonte: [1]

Na década de 70 cada país tinha suas normas para a gestão da qualidade. Os EUA passaram a exigir as normas MIL-Q9858A e MIL-145208A para fornecedores de bens e serviços. Em 1979 a Inglaterra criou a BS575 para sistemas da qualidade, outros campos específicos tais como nuclear, médico, petróleo também criaram suas normas. Então, na década de 80 a ISO International Organization for Standardization estabeleceu o comitê técnico TC 176 - Garantia da Qualidade que consolidou, em 1987, e publicou os conteúdos adquiridos sobre a nomenclatura normas ISO 9000. A palavra ISO vem do grego que significa igual, adotou-se essa nomenclatura para que fosse unificada a todos os países que quisessem aderir [1][3].

As normas série ISO 9000 tratam de sistemas de gerenciamento da qualidade, com objetivo de assegurar qualidade do produto e serviço desde sua concepção, passando pela fabricação, expedição, e pós-venda, tendo como foco redução de desperdícios, melhoria contínua, melhoria na relação cliente-fornecedor e assim, aumentando a produtividade e intensificando os lucros das organizações [2][3].

\subsection{Definições da Qualidade}

a) O que é Qualidade?

A norma ISO 8402:1987 define a qualidade da seguinte maneira:

"a totalidade de propriedades e características de um produto ou serviço que confere sua habilidade em satisfazer necessidades explícitas ou implícitas" [2].

Atualmente, a ISO 9000:2015 define como:

"grau em que um conjunto de características inerentes de um objeto satisfaz requisitos" [10].

Juran a definiu como adequação ao uso, Deming argumentou que a qualidade só pode ser definida em termos de quem a avalia, Feigenbaum avaliou como sendo o atendimento às expectativas do cliente. Ferreira conceituou que a noção de qualidade que faz o cliente aceitar ou recusar um produto. Ou seja, todos os autores acima colocaram o cliente como detentor da qualidade [1][3][5].

b) O que é Gerenciamento da Qualidade?

Para se ter um gerenciamento da qualidade numa empresa é necessário primeiro definir claramente os objetivos, estabelecendo as normas utilizadas e, assim, definindo um sistema de qualidade [2].

c) $O$ que é ciclo PDCA?

O PDCA "Plan-Do-Check-Act" tem uma abordagem cíclica impulsionando a melhoria contínua dos produtos e serviços [4].

A ISO 9001:2008 o define da seguinte maneira: 
Plan (planejar): estabelecer os objetivos e processos necessários para gerar resultados de acordo com os requisitos do cliente e com as políticas da organização.

Do (fazer): implementar os processos.

Check (checar): monitorar e medir processos e produtos em relação às políticas, aos objetivos e aos requisitos para o produto e relatar os resultados.

Act (agir): executar ações para promover continua-mente a melhoria do desempenho do processo [6].

d) O que é melhoria contínua?

O conceito de melhoria contínua origina-se da palavra japonesa 'kaizen' que tem como lema que tudo é melhorável. É a aplicação constante do ciclo PDCA.

e) O que é ação corretiva e ação preventiva?

Uma ação corretiva é uma ação realizada para corrigir uma anomalia existente.

Uma ação preventiva é uma ação tomada para inibir uma anomalia potencial para que esta não venha a ocorrer [4].

f) $O$ que é rastreabilidade?

Rastreabilidade é quando se documenta um processo a ponto de que se saiba quem, quando e onde foram realizadas todas as etapas do mesmo [2].

g) O que é Manual da Qualidade?

É um documento que contém exemplo de todos os documentos e procedimentos utilizados para 0 gerenciamento da qualidade [2].

h) O que são auditorias da qualidade?

São auditorias periódicas com o objetivo de identificar oportunidades de melhoria e avaliar o grau de maturidade do negócio em relação ao gerenciamento da qualidade. Seus resultados são entradas para as reuniões de análise crítica pela direção [4].

i) O que são as reuniões de análise crítica?

São reuniões periódicas feitas pela alta direção com objetivo de avaliar a eficácia, suficiência e adequação do sistema de gestão da qualidade, melhorando-o continuamente [6][7].

\section{Objetivos principais e específicos}

\subsection{Objetivo principal}

Fornecer uma visão comparativa da evolução das versões das normas ISO 9001.

\subsection{Objetivos específicos}

- Comparar as estruturas, os enfoques e os requisitos trazidos pela norma em cada nova versão;

- Analisar criticamente o contexto brasileiro em cada época de mudanças na norma;

- Analisar criticamente a visão de mercado em cada época de mudanças na norma;

- Refletir sobre os princípios e ferramentas da norma: kaizen e PDCA.

\section{Metodologia}

A metodologia aplicada neste trabalho foi a pesquisa bibliográfica dos principais autores e a análise comparativa comentada das versões das normas ISO 9001.

\section{Análise Crítica}

Ao adotar a família de normas do Sistema de Gestão da Qualidade, normas série ISO 9000, a empresa deve estar comprometida em adequar-se para colher os benefícios da certificação ISO 9001 mediante seus stakeholders (partes interessadas) [2].

Maekawa e seus colaboradores identificaram as principais motivações do empresário brasileiro em adequar-se as normas ISO 9001, como sendo a possibilidade de melhoria na organização interna, maior eficiência produtiva e maior confiabilidade da marca [11].

\subsection{Norma ISO 9001:1987}

No final da década de 80 o Brasil estava abrindo a economia, a globalização era um fenômeno ainda novo porém crescente, as normas ISO 9000 possuíam aceitação na Comunidade Européia (CE) e no Comitê Europeu de Normas (CEN). Após 1992 para evitar o "ambiente harmonizado" a Associação Europeia de Livre Comércio (EFTA) proibiu a recusa dos órgãos governamentais em comprar de qualquer companhia sócia à CE para evitar abusos econômicos e tecnológicos dos países mais desenvolvidos. Com isso tornava interessantes para países menos desenvolvidos, como o Brasil, aderirem à esta norma [2][3].

Inicialmente, a norma ISO 9001:1987 tinha como enfoque a garantia da qualidade. A exigência primordial para se implantar a norma ISO http://dx.doi.org/10.25286/repa.v2i4.718 
9001:1987 era a criação da Política da Qualidade onde a alta gerência (na norma ISO 9001:2015 denominada por alta direção) afirma seu comprometimento em gerenciar o negócio de acordo com esta norma, tendo a responsabilidade de instruir todo o staff em todos os níveis: estratégico, tático e operacional [1][2][8].

Além da Política da Qualidade, a norma ISO 9001:1987 exigia outros documentos, a Figura 1 apresenta o triângulo de documentação da qualidade, que específica os documentos necessários, e seus respectivos níveis, para adaptar o negócio ao sistema da qualidade ISO 9001[3].

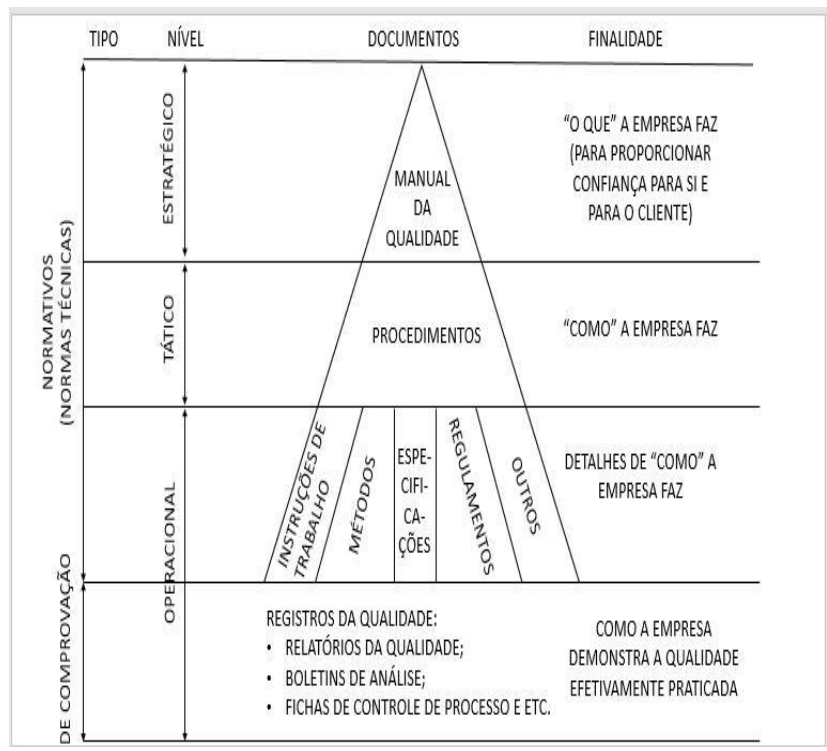

Figura 1 - Triângulo de documentação da qualidade ISO 9001:1987

Fonte: [3]

A família de normas ISO 9000:1987 abrange o conjunto de normas mostrados na Figura 2, sendo as normas ISO 9001, 9002 e 9003 auditáveis e as demais auxiliaries no processo de implementação do gerenciamento da qualidade.

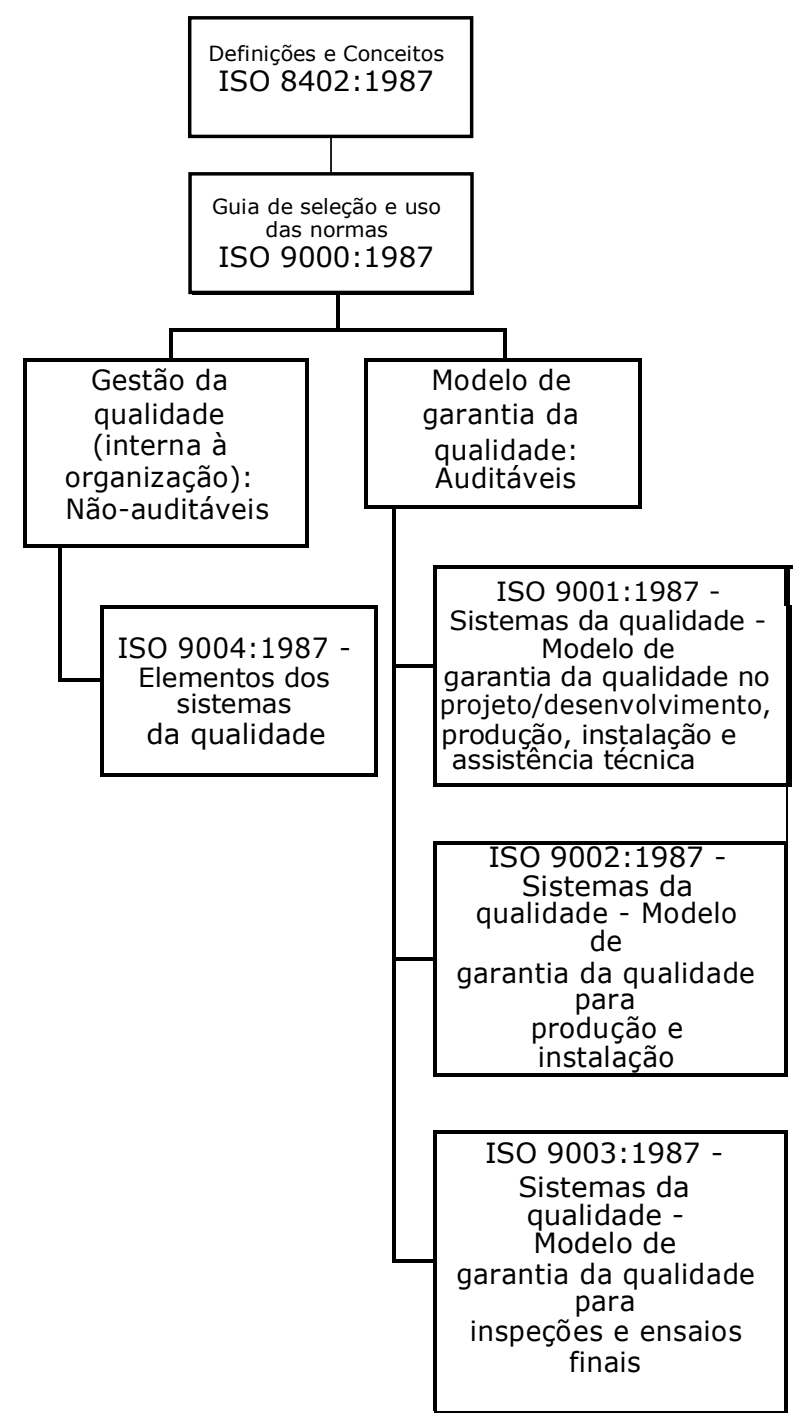

Figura 2: Conjunto de normas série ISO 9000:1987 Fonte: [3].

\subsection{Norma ISO 9001:1994}

Os requisitos das normas da família ISO 9000:1994 vieram com estrutura semelhante as normas ISO 9000:1987. Mantendo as normas ISO 9001, 9002 e 9003 como auditáveis no mesmo modelo da Figura 2, porém manteve a norma ISO 9001 como principal e alinhou os formatos das normas ISO 9002 e 9003 conforme esta.

Uma das principais mudanças da norma ISO 9001:1994 foi a exigência de procedimentos documentados para a maioria dos elementos da norma, também passou a aceitar meios eletrônicos como forma de controle e emissão de registros da qualidade. Esta norma fortalece e torna obrigatório o item referente a liderança da qualidade total, já existente na norma ISO 9001:1987, exigindo a 
determinação de um representante da qualidade com hierarquia executiva.

O enfoque da norma ISO 9001:1994 obteve um caráter preventivo com a criação do requisito ação preventiva, em complemento à norma ISO 9001:1987 que tinha um enfoque reativo, exigindo apenas o requisito ação corretiva que foi mantido.

Outra abrangência dessa norma está na exigência do gerenciamento da qualidade por parte do subfornecedor, a norma anterior transferia esta responsabilidade para o fornecedor. A ISO 9001:1994 tornou possível a auditoria de subfornecedores do negócio auditado, conforme requisitos do contrato estabelecido entre ambos. Houve, também, algumas mudanças de nomenclatura, como a substituição do requisito 4.19 de assistência técnica para serviços associados [1][4].

A norma ISO 9001:1994 veio para complementar a norma ISO 9001:1987, mantendo o enfoque na garantia da qualidade. Nos anos 90 a abertura dos mercados já era um fenômeno latente no Brasil, porém o país ainda enfrentava problemas na economia e inflação elevada. Com o surgimento do Plano Real e a estabilização da economia internacional, a adesão às certificações ISO 9001 no Brasil começaram a ser maiores, conforme Figura 3, esta norma veio para contribuir no aumento da produtividade e qualidade dos seus produtos e processos, certificando internacionalmente e assim facilitando a expansão dos produtos nacionais em outros mercados [1].

Os empresários brasileiros que aderiram à ISO 9001 buscavam reconhecimento internacional, atualização de seu sistema de qualidade, acatar decisões de cúpula no âmbito da corporação e atender exigências contratuais [11].

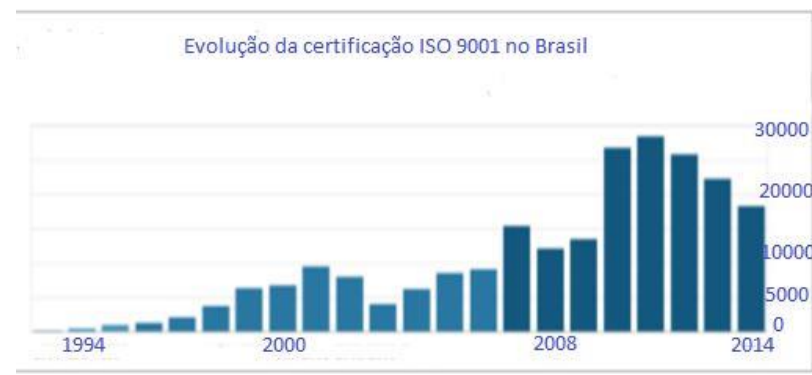

Figura 3: Evolução da certificação ISO 9001 no Brasil Fonte: [1].

\subsection{Norma ISO 9001:2000}

No início do século XXI o Brasil apresentava uma reação favorável da economia devido ao plano Real, alinhado a isso políticas de estímulo ao consumo foram implementadas pelo governo, estes fatores levaram ao aquecimento da economia o que justifica o crescimento das certificações ISO 9001 no Brasil, conforme mostra a Figura 3.

Com a entrada do novo século e as mudanças tecnológicas latentes, as normas ISO precisaram se adaptar, houve fortes mudanças estruturais na norma com a aplicação do conceito dos 8 princípios da qualidade, mostrados na Tabela 2. Esta mudança estrutural visava obter uma conformidade com a norma ISO 14001 aplicada à gestão ambiental.

Tabela 2: Princípios da qualidade abordados na norma ISO 9001:2000

\begin{tabular}{|l|}
\hline \multicolumn{1}{|c|}{ NBR ISO $9001: 2000$} \\
\hline Foco no cliente \\
\hline Liderança \\
\hline Envolvimento das pessoas \\
\hline Abordagem por processos \\
\hline $\begin{array}{l}\text { Abordagem sistêmica de ges- } \\
\text { tão }\end{array}$ \\
\hline Melhoria contínua \\
\hline $\begin{array}{l}\text { Abordagem de tomada de de- } \\
\text { cisões baseadas em fatos }\end{array}$ \\
\hline $\begin{array}{l}\text { Relações mutuamente bené- } \\
\text { ficas com fornecedores }\end{array}$ \\
\hline
\end{tabular}

Fonte: [1].

A partir da norma ISO 9001:2000 foram canceladas as normas da série ISO 9002 e ISO 9003 passando a ISO 9001 a ser uma só para todos os tipos de negócio. O enfoque aplicado nesta norma passou de garantia para gestão da qualidade, essa nova sistemática aboliu o conceito de que qualidade é feita através de inspeções, a nova ideia central é gerir os processos para evitar erros. O conceito principal passou de controlar para gerir. Neste enfoque a norma ISO 9001:2000 promovia a adoção de um abordagem de processos baseada no uso do PDCA e descrevendo a cadeia de fornecimento conforme mostrado na Figura 4, diferen-ciando os clientes apenas como interno e externo [1][4][7]. 


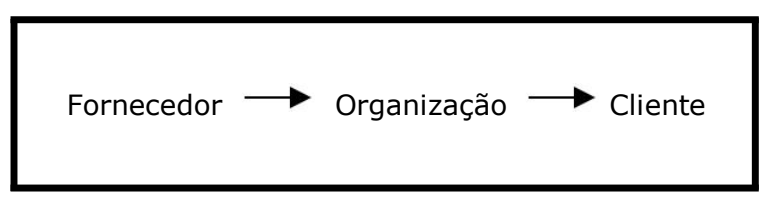

Figura 4: Cadeia de fornecimento Fonte: [7].

Outro ponto novo na norma ISO $9001: 2000$ foi a aceitação de itens não-aplicáveis, conforme o negócio em questão, porém isto é válido apenas para os itens da secção 7 - Realização do produto. Essa norma específica a existência de procedimentos documentados para os seguintes requisitos: controle de documentos, controle de registros, auditoria interna, controle de produto não-conforme, ação corretiva e ação preventiva [1][7].

A satisfação do cliente passou a ser medida; no Brasil, os empresários começaram a sentir a pressão de seus clientes, principalmente externos, pela presença de uma certificação em qualidade, o que também contribuiu para elevar a quantidade de certificações da norma ISO 9001, conforme mostrado na Figura 3. O direcionamento para me-Ihoria contínua tornou-se um diferencial da organização e a alta direção não poderia mais deixar a responsabilidade da qualidade apenas para o seu representante [4][11].

\subsection{Norma ISO 9001:2008}

No ano biênio 2008/2009 ocorreu uma crise econômica mundial, causando instabilidade, que se refletiu também no Brasil. As certificações ISO 9001 diminuíram, conforme mostra a Figura 3.

Os requisitos da norma ISO 9001:2008 vieram com a mesma estrutura da norma ISO 9001:2000, mostrado na Tabela 2. Fortaleceu a abordagem por processos através do uso do PDCA e facilitou a interpretação dos conceitos da norma. Manteve também os 8 princípios da qualidade [1].

Nos requisitos de generalidades houve uma abrangência no conceito produto, antes era apenas aplicado para o produto pretendido ou requerido por um cliente, a ISO 9001:2008 incluiu qualquer resultado pretendido, resultante dos processos de realização do produto. Essa versão manteve a opção de não aplicação de requisitos para itens da seção 7.

Nos quesitos gerais de Sistemas da Qualidade, a norma trouxe a definição de processo terceirizado ampliando o controle do negócio com os processos considerados externos, devendo todos aderirem aos requisitos da secção 7 .

No requisito 6.2.1 foi incluída uma nota reforçando a influência das pessoas nas conformidades dos requisitos, para alertar a importância que deve ser 61 dada à capacitação da mão-de-obra. O requisito 6.4 explicou o termo ambiente de trabalho como sendo as condições sob as quais o trabalho é executado (ruído, umidade, temperatura, iluminação e condições meteorológicas).

No requisito 7.2.1 foi definida as atividades de pós-entrega como sendo ações sob condições de garantia, obrigações contratuais, tais como serviços de manutenção e suplementares, como reciclagem e descarte.

No requisito 7.3.1 foi incluída uma nota onde deixa a critério da organização a forma de registrar os pontos do projeto. No requisito 7.3.3 foi incluída uma nota sobre a preservação do produto. 0 requisito 7.6 explica melhor como evidenciar o uso de programas de computadores para medição e monitoramento.

No requisito 8.2.1 a nota explica melhor como evidenciar a satisfação do cliente. Em nota no requisito 8.2.3 a norma recomendou que a organização considere o tipo e a extensão de monitoramento ou medição apropriados ao processo devido aos impactos sobre conformidade aos requisitos e eficácia do sistema de gestão da qualidade [6].

Na época desta nova versão, as normas ISO 9001 e a qualidade já eram conhecidas e consolidadas, portanto tornou-se um bom marketing para o negócio ser certificada nesta norma, melhorando a imagem da marca perante seus clientes. No Brasil, além do Sistema de Gestão da Qualidade, sistemas de gestão de segurança e ambiental, tais como a OHSAS 18001 de Saúde e Segurança do Trabalho e a ISO 14001 de Gestão Ambiental que são compatíveis com a norma ISO 9001, passaram a ser exigidas pelos clientes e pelas partes envolvidas. Portanto passou a ser interessante para o empresário aderir a um sistema integrado de gestão, abrangendo estas três normas [11].

\subsection{Norma ISO 9001:2015}

O conceito da norma ISO 9001:2015 considera o maior nível de instrução e exigência da sociedade, visto que, além dos objetivos já tratados nas normas anteriores, a imagem da empresa perante a sociedade também é um item a ser considerado na gestão da qualidade, e que hoje o contexto de trabalho é mais acelerado, globalizado e tem como principal recurso o conhecimento. $O$ foco em questão não é mais apenas satisfação dos clientes e sim de todas as partes interessadas.

Nesse contexto de parte interessadas, a norma ISO 9001:2015 aborda um pensamento baseado na gestão de riscos, em que a organização deverá identificar quais são as partes interessadas 
pertinentes que podem contribuir para a sustentabilidade do seu negócio e assim abrange o requisito de ações preventivas existentes desde a norma ISO 9001:1994. A abordagem por processos e o enfoque na gestão da qualidade são mantidos. A norma eliminou a figura do representante da qualidade/direção, surgindo o papel da liderança em todos os níveis organizacionais, com propósito de direcionar e criar condições para o engajamento de todos nos objetivos da qualidade [8].

A norma ISO 9001:2015, estruturalmente, usou um conceito desenvolvido pela ISO com o objetivo de unificar/definir estruturas, requisitos e terminologias de todas suas normas de gestão, o qual chamou de Anexo SL. Uma estrutura de alto nível conforme mostrado na Tabela 3 [9].
Tabela 3: Estrutura do Anexo SL

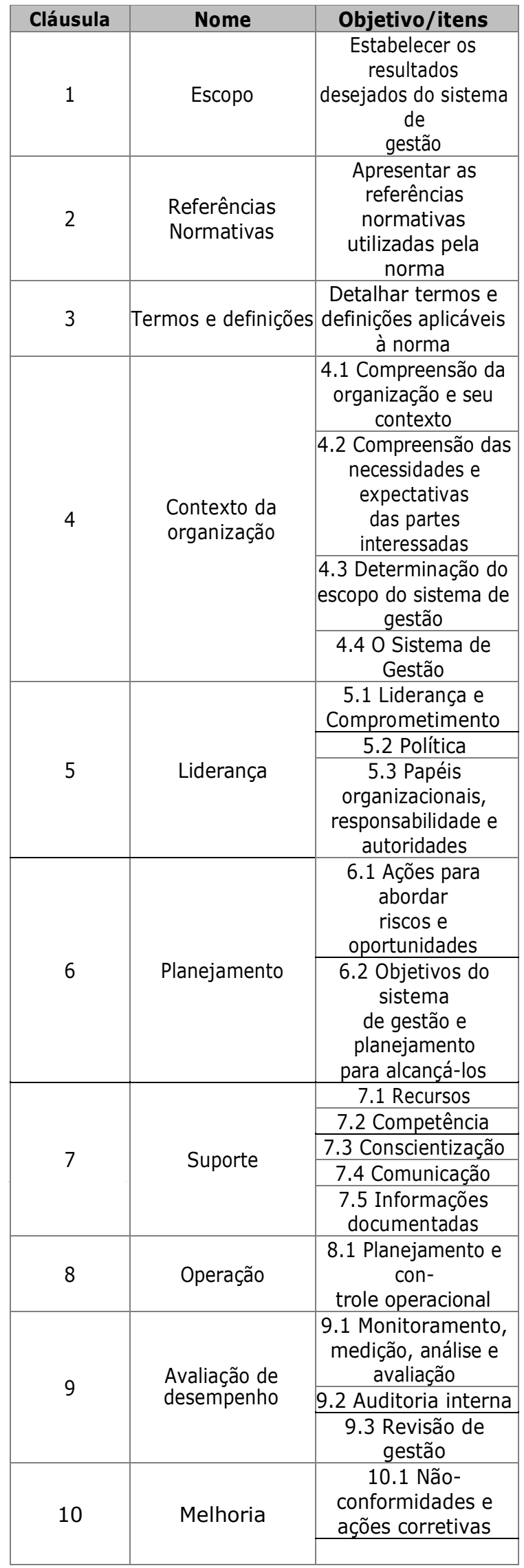


A norma ISO 9001:2015 abordou os princípios da qualidade, existentes desde a versão ISO 9001:2000, de uma maneira diferente, conforme mostra a Tabela 4.

Tabela 4: Comparativo entre os princípios da qualidade abordados nas normas ISO 9001

\begin{tabular}{|c|c|}
\hline $\begin{array}{c}\text { NBR ISO } \\
\text { 9001:2000e NBR } \\
\text { ISO } 9001: 2008\end{array}$ & $\begin{array}{c}\text { NBR ISO } \\
9001: 2015\end{array}$ \\
\hline Foco no cliente & Foco no cliente \\
\hline Liderança & Liderança \\
\hline $\begin{array}{l}\text { Envolvimento das } \\
\text { pessoas }\end{array}$ & $\begin{array}{l}\text { Envolvimento das } \\
\text { pessoas }\end{array}$ \\
\hline $\begin{array}{l}\text { Abordagem por } \\
\text { processos }\end{array}$ & $\begin{array}{l}\text { Abordagem por } \\
\text { processos }\end{array}$ \\
\hline $\begin{array}{l}\text { Abordagem } \\
\text { sistêmica de } \\
\text { gestão }\end{array}$ & - \\
\hline Melhoria contínua & Melhoria \\
\hline $\begin{array}{c}\text { Abordagem } \\
\text { de tomada de } \\
\text { decisões baseadas em } \\
\text { fatos }\end{array}$ & $\begin{array}{c}\text { Tomada de } \\
\text { decisão baseada } \\
\text { em evidências }\end{array}$ \\
\hline $\begin{array}{c}\text { Relações } \\
\text { Mutuamente } \\
\text { benéficas com } \\
\text { fornecedores }\end{array}$ & $\begin{array}{l}\text { Gestão das } \\
\text { relações }\end{array}$ \\
\hline
\end{tabular}

A norma ISO 9000:2015 - Sistema de Gestão da Qualidade - Fundamentos e Vocabulários apresenta justifica-tiva, principais benefícios e ações possíveis, para auxiliar na implementação da norma ISO 9001:2015 [10].

A norma ISO 9001:2015 não estabelece, mandatoriamente, a necessidade de procedimentos documentados e de um manual da qualidade como determinava a norma ISO 9001:1987 com seu triângulo da qualidade, apresentado na Figura 1, substituindo estes pelo termo informação documentada, e assim, deixando a cargo das empresas como proceder quanto às comprovações dos requisitos [8].

Esta nova versão chega ao Brasil em um momento onde uma empresa com certificação ISO 9001:2008, a Samarco, causa um grande prejuízo ambiental ao país, isto alerta ao fato de como essa e outras normas estão sendo implementadas, e amplia a importância de que as auditorias sejam realizadas tendo como foco principal o como as tarefas são feitas e como as lideranças estão agindo na gestão dos processos. Como a imagem da empresa está associada ao 63 respeito ao meio ambiente e segurança dos trabalhadores, desastres como esses tem efeito negativo sobre a gestão da qualidade [1].

Outros fatores de dificuldade no país hoje são: impeachment, instabilidade econômica e retração do Mercado.

A Tabela 5 apresenta e compara as estruturas e requisitos de todas as normas ISO 9001, mostrando a forte evolução desta norma. Nas NBR ISO 9001:1987 e NBR ISO 9001:1994 manteve-se a mesma estrutura, porém foram modificados alguns requisitos. Já as NBR ISO 9001:2000 e NBR ISO 9001:2008 vieram com estrutura e requisitos diferentes das duas primeiras, porém sem modificações entre si. A versão atual, norma NBR ISO 9001:2015, veio repaginada, com estrutura e requisitos, de acordo com o anexo $\mathrm{SL}$, mostrando na Tabela 3. 
Revista de Engenharia e Pesquisa Aplicada (2017) Vol.2 No.4.

\begin{tabular}{|c|c|c|c|c|}
\hline NBR ISO 9001:1987 & NBR ISO 9001:1994 & NBR ISO 9001:2000 & NBR ISO 9001:2008 & NBR ISO 9001:2015 \\
\hline $\begin{array}{c}\text { 4.1 Responsabilidade da } \\
\text { administração }\end{array}$ & $\begin{array}{c}4.1 \text { Responsabilidade da } \\
\text { administração }\end{array}$ & $\begin{array}{l}\text { 4. Sistema de Gestão da } \\
\text { Qualidade }\end{array}$ & $\begin{array}{l}\text { 4. Sistema de Gestão da } \\
\text { Qualidade }\end{array}$ & 4. Contexto da organização \\
\hline $\begin{array}{l}4.2 \text { Sistema da } \\
\text { qualidade }\end{array}$ & $\begin{array}{c}4.2 \text { Sistema da } \\
\text { qualidade }\end{array}$ & $\begin{array}{l}\text { 5. Responsabilidade da } \\
\text { direção }\end{array}$ & $\begin{array}{l}\text { 5. Responsabilidade da } \\
\text { di- } \\
\text { reção }\end{array}$ & 5. Liderança \\
\hline $\begin{array}{c}\text { 4.3 Análise crítica de } \\
\text { contrato }\end{array}$ & $\begin{array}{c}\text { 4.3 Análise crítica de } \\
\text { contrato }\end{array}$ & 6. Gestão de Recursos & 6. Gestão de Recursos & 6. Planejamento \\
\hline 4.4 Controle de projeto & 4.4 Controle de projeto & $\begin{array}{l}\text { 7. Realização do } \\
\text { Produto }\end{array}$ & 7. Realização do Produto & 7. Apoio \\
\hline $\begin{array}{l}\text { 4.5 Controle de docu- } \\
\text { mentos }\end{array}$ & $\begin{array}{c}4.5 \text { Controle de docu- } \\
\text { mentos e de dados }\end{array}$ & $\begin{array}{c}\text { 8. Medição, Análise e } \\
\text { Melhoria }\end{array}$ & $\begin{array}{l}\text { 8. Medição, Análise e Me- } \\
\text { Ihoria }\end{array}$ & 8. Operação \\
\hline 4.6 Aquisição & 4.6 Aquisição & & & 9. Avaliação de desempenho \\
\hline $\begin{array}{c}\text { 4.7 Produto fornecido } \\
\text { pelo comprador }\end{array}$ & $\begin{array}{l}\text { 4.7 Controle de produto } \\
\text { fornecido pelo cliente }\end{array}$ & & & 10. Melhoria \\
\hline $\begin{array}{l}4.8 \text { Identificação e ras- } \\
\text { treabilidade do produto }\end{array}$ & $\begin{array}{l}\text { 4.8 Identificação e ras- } \\
\text { treabilidade do produto }\end{array}$ & & & \\
\hline $\begin{array}{c}4.9 \text { Controle de } \\
\text { processo } \\
\end{array}$ & $\begin{array}{c}4.9 \text { Controle de } \\
\text { processo }\end{array}$ & & & \\
\hline 4.10 Inspeções e ensaios & 4.10 Inspeções e ensaios & & & \\
\hline $\begin{array}{c}4.11 \text { Equipamentos } \\
\text { de inspeção, medição } \\
\text { e ensaios }\end{array}$ & $\begin{array}{c}4.11 \text { Controle de } \\
\text { equipamentos de } \\
\text { inspeção, medição e } \\
\text { uso }\end{array}$ & & & \\
\hline $\begin{array}{l}4.12 \text { Situação de } \\
\text { inspeção e ensaios }\end{array}$ & $\begin{array}{c}4.12 \text { Situação de } \\
\text { inspeção e ensaios }\end{array}$ & & & \\
\hline $\begin{array}{l}4.13 \text { Controle de } \\
\text { produto não } \\
\text { conforme }\end{array}$ & $\begin{array}{l}4.13 \text { Controle de } \\
\text { produto não } \\
\text { conforme }\end{array}$ & & & \\
\hline 4.14 Ação corretiva & $\begin{array}{c}\text { 4.14 Ação corretiva e } \\
\text { ação preventiva }\end{array}$ & & & \\
\hline $\begin{array}{l}\text { 4.15 Manuseio, } \\
\text { armazenamento, } \\
\text { embalagem e } \\
\text { expedição }\end{array}$ & $\begin{array}{c}4.15 \text { Manuseio, } \\
\text { armazenamento, } \\
\text { embalagem, } \\
\text { preservação e } \\
\text { entrega }\end{array}$ & & & \\
\hline $\begin{array}{l}\text { 4.16 Registros da } \\
\text { qualidade }\end{array}$ & $\begin{array}{l}4.16 \text { Controle e } \\
\text { registros da } \\
\text { qualidade }\end{array}$ & & & \\
\hline $\begin{array}{l}\text { 4.17 Auditorias } \\
\text { internas da qualidade }\end{array}$ & $\begin{array}{c}\text { 4.17 Auditorias } \\
\text { internas da qualidade }\end{array}$ & & & \\
\hline 4.18 Treinamento & 4.18 Treinamento & & & \\
\hline $\begin{array}{l}4.19 \text { Assistência } \\
\text { técnica }\end{array}$ & $\begin{array}{l}4.19 \text { Serviços } \\
\text { associados }\end{array}$ & & & \\
\hline $\begin{array}{l}\text { 4.20 Técnicas } \\
\text { estatísticas }\end{array}$ & $\begin{array}{l}\text { 4.20 Técnicas } \\
\text { estatísticas }\end{array}$ & & & \\
\hline
\end{tabular}

Tabela 5: Comparação entre os requisitos das normas NBR ISO 9001:1987/1994/2000/2008/2015

Fonte: $[3][5][6][7][8]$. 


\section{Conclusão}

As definições de qualidade em geral focaram no cliente como detentor da qualidade final do produto, porém nem sempre todos os desejos deste serão satisfeitos. Fatores como processos de fabricação, custo, tecnologia disponível, materiais, entre outros recursos, são escassos, determinando padrões de produtos disponíveis no mercado. A norma ISO 9001 estabelece um modelo de gestão, baseado principalmente no PDCA e kaizen, a ser seguido pelas empresas possibilitando que seus produtos estejam conforme padrões préestabelecidos.

A norma ISO 9001:1987 teve como foco procedimentos e como enfoque a garantia da qualidade; a primeira revisão da norma foi feita em 1994 introduzindo o conceito de ações preventivas; a revisão de 2000 mudou o enfoque, antes tratavase de garantia da qualidade e mudou para gestão da qualidade, com isso a qualidade não seria mais garantida apenas pela equipe da qualidade mas gerida por ela, e a garantia seria dada por todos. 0 foco da norma começa a se expandir. Em 2008 a nova revisão fortaleceu a abordagem por processos; a última revisão foi feita em 2015 introduzindo, em toda a norma, um pensamento baseado na gestão de riscos e eliminou a figura do representante da qualidade/direção, com a criação do requisito liderança.

O modelo de gestão trazido na ISO 9001:1987 ajudava a organizar o negócio, através de documentação e determinava quais eram os tipos de documentos necessários, a ISO 9001:1994 manteve estes documentos incluindo a necessidade de se prevenir de que erros ocorridos tornassem a aparecer. A ISO 9001:2000 enxugou a documentação e focou num modelo integrado, pois as normas ISO 14001 , para gestão ambiental, já tinham sido criadas, a ISO 9001:2008 ajudou a consolidar os conceitos da versão 2000 e a norma atual, ISO 9001:2015, elimina a ideia de qualidade voltada apenas ao cliente consumidor e amplia a todas as partes interessadas. Abrangendo o conceito de prevenir para que o erro ocorrido seja sanado, para que o erro não venha a ocorrer. Nesse contexto interessa, também, saber qual a percepção que produtos e serviços têm no mercado, quais os benefícios e prováveis impactos negativos. A imagem dos produtos e serviços está diretamente ligada à percepção da sua qualidade.
Estudar a evolução da norma ISO 9001 é estudar a evolução da qualidade. Esta norma, que só começou a ser publicada nos anos 80 , consolida o que os autores pioneiros da qualidade (Tabela 1) pregavam e continua se modernizando até a versão atual (ISO 9001:2015), que traz o Anexo SL com objetivo de unificar estruturas, requisitos e terminologia de normas de sistemas de gestão por entender que a qualidade não é apenas um departamento ou mais uma etapa do processo, mas sim que a qualidade é o todo; sendo, assim, aplicada no dia-a-dia, como o objetivo principal.

\section{Referências}

[1] S. Chaves, M. Campello. A qualidade e a evolução das normas série ISO 9000. XIII Simpósio de Excelência na Gestão e Tecnologia, 2016.

[2] B. Rothery. Tradução: R. C. Loverri; revisão técnica: A. I. Macachero. ISO 9000. Makron Books: São Paulo, 1993.

[3] M. Maranhão. ISO série 9000: Manual de Implementação/ 2a edição. Qualitymark Editora: Rio de Janeiro, 1994.

[4] L. F. S. D. Reis. ISO 9000: auditorias de Sistema da qualidade. Editora Érica: São Paulo, 1995.

[5] L. E. Sartorelli. Análise Crítica da Implantação da ISO 9001/1994 com alguns Requisitos da ISO 9001:2000 à Luz dos Principais Autores da Qualidade. Trabalho Final de Mestrado Profissional, Universidade Estadual de Campinas, Maio 2003.

[6] ABNT NBR ISO 9001:2008. Sistemas de gestão da qualidade - Requisitos. ISBN 978-85-0701100-2. ISO 2008. ABNT 2008.

[7] NBR ISO 9001:2000. Sistemas de gestão da qual-idade - Requisitos. ISO 2000.

[8] ABNT NBR ISO 9001:2015. Sistemas de gestão da qualidade - Requisitos. ISBN 978-85-0705801-4. ISO 2015. ABNT 2015.

[9] Bsigroup, Apresentando o Anexo SL - a nova estrutura de alto nível para todas as normas 
de sistema de gestão do futuro: abordando a mudança, www.bsigroup.com/pt-BR, 1/05/2017.

[10] ABNT NBR ISO 9000:2015 - Sistema de Gestão da Qualidade - Fundamentos e Vocabulários. ISO 2015.

[11] R. Maekara, M. M. Carvalho, O. J. Oliveira. Um estudo sobre a certificação ISO 9001 no Brasil: mapeamento de motivações, benefícios e dificuldades. Gest. Prof., São Carlos, v. 20, n. 4, p. 763-779, 2013. 